\title{
COMPOSTOS BIOATIVOS E ATIVIDADE ANTIOXIDANTE DO CAFÉ CONILON SUBMETIDO A DIFERENTES GRAUS DE TORRA
}

\author{
Sérgio Antônio Lemos de Morais, Francisco José Tôrres de Aquino*, Priscilla Mendes do Nascimento, Evandro Afonso do \\ Nascimento e Roberto Chang \\ Instituto de Química, Universidade Federal de Uberlândia, CP 593, 38408-100 Uberlândia - MG, Brasil
}

Recebido em 19/2/08; aceito em 10/10/08; publicado na web em 5/2/09

\begin{abstract}
BIOACTIVE COMPOUNDS AND ANTIOXIDANT ACTIVITY OF CONILON COFFEE SUBMITTED TO DIFFERENT DEGREES OF ROASTING. The bioactive compounds and antioxidant activity presented by Conilon coffee (C. Canephora) variety, produced in the Espírito Santo State, Brazil, were quantified. The light roast coffee showed the highest level of total phenols, trigonelline, caffeic and chlorogenic acids. The proanthocyanidin level was the highest for dark roast coffee, while caffeine level didn't show significative changes for the light and middle roast coffees. All the Conilon coffee extracts showed antioxidant activity depending on bioactive compounds concentration and roasting degree. The coffee samples submitted to a light roasting degree showed the highest antioxidant activity.
\end{abstract}

Keywords: Coffea canephora; bioactive compounds; antioxidant activity.

\section{INTRODUÇÃO}

O Brasil é o maior produtor mundial de grãos de café e números da safra 2006/2007 mostram que o país exportou 27 milhões de sacas de café verde. Segundo a Associação Brasileira da Indústria de Café (ABIC), o consumo interno de café foi de 16,3 milhões de sacas entre novembro/2006 e outubro/2007. Para 2010, a estimativa é de 21 milhões, o que fará do país o maior consumidor do produto no mundo, superando a posição ocupada pelos Estados Unidos, com média que atinge 20 milhões. ${ }^{1}$

A qualidade é o fator fundamental para valorização do café e está associada principalmente na condução adequada dos procedimentos após a colheita, ao tipo e à espécie, aos diferentes graus de torra e à composição dos diversos constituintes químicos do grão, destacando-se compostos nitrogenados (alcalóides, trigonelina, proteínas e aminoácidos livres), carboidratos (polissacarídeos e monossacarídeos), lipídios (ácidos graxos, diterpenos), ácidos clorogênicos, flavonóides, vitaminas, minerais e óleo essencial (constituintes voláteis). ${ }^{2,3}$

A designação "robusta", ou café robusta, engloba uma ampla variedade de cafés da espécie Coffea canephora Pierre ex Froehner, tais como conilon ou konillou, guarini, apoatã, laurenti, robusta, outros. ${ }^{4-6}$ No Brasil, a grande maioria das lavouras de café conilon localiza-se no estado do Espírito Santo, seu maior produtor, destacando-se ainda os estados de São Paulo, Paraná, Bahia e Rondônia. ${ }^{7}$ O café conilon é adicionado ao café arábica para acentuar o sabor e o corpo da bebida (blend) e na preparação de café solúvel. ${ }^{5}$

Existe uma vasta literatura que relata o potencial dos compostos bioativos ou componentes funcionais na ação contra os males da hipertensão, doenças cardiovasculares, câncer entre outras. ${ }^{8-20}$

Além da cafeína, o café apresenta outras substâncias bioativas como a trigonelina, compostos fenólicos (em que se destacam os ácidos clorogênicos) e compostos resultantes da reação de Maillard, como as melanoidinas. ${ }^{21,22}$ Os compostos fenólicos constituem uma das principais classes de antioxidantes naturais. Eles são largamente

*e-mail: aquino@iqufu.ufu.br distribuídos em frutos, legumes, grãos, sementes, folhas, raízes, cascas, dentre outros materiais. Estes constituintes são capazes de retardar o envelhecimento e o aparecimento de doenças, e até de impedí-las. ${ }^{10-20}$

Os constituintes dos cafés são afetados pelo grau de torra. A trigonelina, presente em torno de $1,0 \%$ no grão cru, durante a torra, pode formar a niacina e diversos componentes voláteis, como piridinas e pirróis e que contribuem para aroma final da bebida. Os compostos fenólicos são parcialmente isomerizados, hidrolisados ou degradados em compostos voláteis de baixa massa molecular. Durante a torra do café, partes destes constituintes fenólicos são incorporadas às melanoidinas ou polimerizadas, formando misturas complexas. ${ }^{23} \mathrm{Os}$ ácidos clorogênicos reagem durante a torra, produzindo compostos ácidos, lactonas e outros derivados fenólicos que contribuem para o aroma e sabor do café, acidez final e adstringência da bebida. ${ }^{24} \mathrm{Em}$ princípio, os teores de cafeína não apresentam diferenças significativas em relação à torra. ${ }^{25}$ As proantocianidinas juntamente com os polifenóis, apresentam sabor adstringente típico. Desta forma, interferem no sabor e aroma após a torra justificando, assim, e em parte, a menor qualidade da bebida preparada somente a partir de grãos de café conilon.

Entre os métodos utilizados para a determinação da atividade antioxidante de compostos orgânicos, encontra-se o método espectrofotométrico baseado na redução da concentração do radical 1,1-difenil-2-picril-hidrazila (DPPH·). Nessa reação a espécie DPPH· é reduzida pelos constituintes antioxidantes presentes nos compostos orgânicos (AH). ${ }^{26-28}$

Na literatura foram encontrados poucos trabalhos acerca do café conilon (ou robusta) cultivado no Brasil. ${ }^{29-39}$ Nenhum deles trata dos compostos bioativos desta variedade produzida no estado do Espírito Santo. Em continuidade aos nossos estudos com cafés, ${ }^{40-46}$ o presente trabalho teve como objetivo caracterizar os compostos bioativos (trigonelina, ácidos clorogênicos, ácido caféico e cafeína), determinar o teor de fenóis totais, teor de óleos essenciais e determinar a atividade antioxidante através da concentração eficiente $\left(\mathrm{CE}_{50}\right)$ em amostras de cafés da espécie Coffea canephora Pierre ex Froehner, cultivar conilon, em função do grau de torra (clara, média e escura). 


\section{PARTE EXPERIMENTAL}

\section{Solventes, reagentes e soluções}

Todos os solventes e reagentes usados foram de grau analítico. O reagente Folin-Ciocalteu foi adquirido da Merck, Brasil. O radical livre DPPH (2,2-difenil-1-picril-hidrazila) e os padrões catequina, ácido gálico, ácido clorogênico, ácido caféico, cafeína e trigonelina foram adquiridos da empresa Sigma Chemical Co. Todas as soluções foram preparadas com reagentes de grau analítico.

\section{Origem das amostras}

Foram utilizadas amostras de café Coffea canephora Pierre ex Froehner, cultivar conilon, safra 2003/04, provenientes da Cooperativa Agrária dos Cafeicultores de São Gabriel Ltda (COOABRIEL), de São Gabriel da Palha, no sul do Espírito Santo.

\section{Delineamento experimental}

Um lote de cerca de $3 \mathrm{~kg}$ de frutos cereja selecionados aleatoriamente foi previamente secado em terreiro de lama asfáltica, descascado e peneirado em malha 16/17, contendo umidade de $11 \%$ (Quimis-Kett 600). Nos experimentos com o café conilon utilizouse o delineamento experimental totalmente casualizado, com três repetições.

As análises químicas foram realizadas no Laboratório de Produtos Naturais, do Instituto de Química da Universidade Federal de Uberlândia.

\section{Torra}

Os grãos foram torrados em um microtorrador elétrico de bancada, marca Pinhalense ${ }^{\circledR}$-BR, modelo TC-0, à temperatura de $190 \pm$ $10{ }^{\circ} \mathrm{C}$. Os pontos das torras clara, média e escura foram atingidos em aproximadamente $6,0 \pm 1,0 ; 8,0 \pm 1,0$ e 10,0 $\pm 1,0 \mathrm{~min}$, respectivamente. As tonalidades das torras foram classificadas de acordo com o sistema de referência usado pela ABIC, que utiliza sistema colorimétrico Roast Color Classification System (AGTRON-SCAA, 1995): clara \#85, média \#55 e escura \#35.47,48 Os grãos torrados foram moídos (moedor elétrico) em granulometria fina (peneira de malha 24 mesh), empacotados em embalagens de polietileno/alumínio, selados e armazenados a $-20^{\circ} \mathrm{C}$, até o momento das análises.

\section{Preparação das amostras}

Os extratos de café foram preparados segundo a metodologia do Instituto Adolfo Lutz, com modificações. ${ }^{49}$ Em um erlenmeyer foram pesados cerca de $10,0 \mathrm{~g}$ de cada amostra e adicionados 100,0 $\mathrm{mL}$ de água fervente. As amostras foram deixadas $1 \mathrm{~min}$ em repouso e filtradas, obtendo-se o extrato de café. Para quantificação recolheuse $1,0 \mathrm{~mL}$ do extrato, o qual foi secado num frasco tarado a $105^{\circ} \mathrm{C}$, durante $6 \mathrm{~h}$, resfriado em um dessecador e pesado.

\section{Determinação de fenóis totais}

A determinação do teor de fenóis totais foi feita pelo o método de Folin-Ciocalteu, com modificações ${ }^{50}$ Em um balão volumétrico de 50,0 $\mathrm{mL}$ foram adicionados $0,1 \mathrm{~mL}$ do extrato de café e o volume do balão completado com água destilada. Desta solução foi retirada uma alíquota de $0,5 \mathrm{~mL}$, que foi transferida para um tubo de ensaio. Adicionaram-se ao extrato de café $2,5 \mathrm{~mL}$ de uma solução aquosa do reativo de Folin-Ciocalteu $10 \%$ e 2,0 mL de uma solução de carbonato de sódio 7,5\% recém-preparadas. A mistura foi mantida em um banho de água a uma temperatura de $50{ }^{\circ} \mathrm{C}$ por 5 min. A amostra foi esfriada e a medida da absorbância registrada a 760 nm (espectrofotômetro UV-Vis Hitachi U-300), utilizando-se cubetas de vidro, tendo como "branco" água e todos os reagentes, menos o extrato de café. Da mesma forma foram feitas as curvas de calibração com soluções aquosas de ácido gálico (concentrações de $10,20,30,40$ e $50 \mu \mathrm{mL}^{-1}$ ). O teor de fenóis totais foi determinado por interpolação das absorbâncias das amostras contra as respectivas curvas de calibração.

\section{Determinação de proantocianidinas}

Para a determinação das proantocianidinas foi utilizado o método da vanilina.$^{51}$ Em um balão volumétrico de $10,0 \mathrm{~mL}$ foram adicionados $0,1 \mathrm{~mL}$ do extrato de café e o balão completado com água destilada. Desta solução foi retirada uma alíquota de 1,0 mL e transferida para um tubo de ensaio. Neste mesmo tubo de ensaio adicionaram-se 2,0 $\mathrm{mL}$ de uma solução recém-preparada de vanilina (Aldrich Co.) em ácido sulfúrico 70\%, na concentração de aproximadamente 10,0 mg $\mathrm{mL}^{-1}$. A mistura foi mantida em um banho de água a uma temperatura de $50{ }^{\circ} \mathrm{C}$ por 15 min. A amostra foi esfriada e a absorvância registrada a $500 \mathrm{~nm}$ (espectrofotômetro UV-Vis Hitachi U-300). Da mesma forma, foi feita uma curva de calibração com catequina (concentrações de 10, 15, 20, 25, 35 e $40 \mu \mathrm{g} \mathrm{mL}^{-1}$ ). As leituras foram registradas contra um branco.

\section{Extração do óleo essencial}

Foi utilizado o procedimento em que se faz uso de um aparelho de Clevenger modificado para extração em contracorrente com diclorometano, de acordo com a metodologia descrita por Godefroot e colaboradores. ${ }^{51}$

\section{Determinação dos teores de trigonelina, cafeína, ácido cafeico e ácidos clorogênicos}

Para determinação de trigonelina, cafeína, ácido cafeíco e ácidos clorogênicos foi utilizado o procedimento de extração com água quente descrito por Vitorino e colaboradores, com pequenas modificações. ${ }^{52}$ Cerca de 2,0 g de cada amostra livre de umidade foram submetidas a uma extração com $20,0 \mathrm{~mL}$ de água em ebulição por 5 min com agitador magnético. $\mathrm{O}$ extrato foi transferido para um balão volumétrico de 100,0 mL e diluído para o volume marcado. Uma alíquota do balão foi filtrada, através de um filtro de ponta de seringa de porosidade de $0,45 \mu \mathrm{m}$, e utilizada nas análises cromatográficas. A cromatografia líquida de alta eficiência (CLAE-UV) foi realizada em um cromatógrafo líquido da marca Shimadzu (JP), modelo SCL-10A VP, equipado com detector SPD-M10A VP do tipo diode-array. Foi usada uma coluna de fase reversa (Shimadzu - JP), modelo CLC-ODS (M), empacotada com grupo octadesil $(25,0 \mathrm{~cm})$. O volume injetado (loop) foi de 20,0 $\mu \mathrm{L}$. Foi usado um sistema de solventes com gradiente de tampão de fosfato (A) preparado com $5 \%$ de solução de fosfato diácido de potássio $0,2 \mathrm{~mol} \mathrm{dm}^{-3}$ e metanol (B). Foram feitas curvas de calibração para os padrões utilizados. A leitura da absorbância foi registrada em $213 \mathrm{~nm}$ para trigonelina, $269 \mathrm{~nm}$ para cafeína, 310 nm para ácido caféico e $323 \mathrm{~nm}$ para o ácido 5-cafeoilquínico, sendo registradas absorbâncias máximas para cada composto.

\section{Análise quantitativa da atividade antioxidante}

A atividade antioxidante dos extratos de café foi determinada através da atividade seqüestrante do radical livre estável 2,2-difenil-1- 
picril-hidrazila (DPPH), que tem sido largamente utilizado para avaliar a capacidade de antioxidantes naturais em seqüestrar radicais livres. ${ }^{53-55}$ A partir do extrato de café foram efetuadas 5 diluições sucessivas $(1,00$; 2,50; 5,00; 7,50 e 10,00 mL em 50,0 mL/água). Para cada solução, foi tomada uma alíquota de $0,10 \mathrm{~mL}$ e adicionado $3,9 \mathrm{~mL}$ de solução de $\mathrm{DPPH}$ (cerca de $50 \mu \mathrm{g} \mathrm{mL^{-1 }}$ em metanol) recentemente preparada. A concentração de DPPH no meio reacional foi calculada conforme curva de calibração obtida por regressão linear. Após a adição do radical DPPH, as soluções de diferentes concentrações foram deixadas em repouso e o decréscimo da absorbância registrado no comprimento de onda de $515 \mathrm{~nm}$ (espectrofotômetro UV-Vis Hitachi U-300) durante $1 \mathrm{~h}$, em intervalos de 5 min entre cada. Uma mistura de 3,9 mL metanol e $0,1 \mathrm{~mL}$ de extrato foi utilizada como branco.

A porcentagem de atividade antioxidante (AA) foi determinada pela Equação 155,56

$\% \mathrm{AA}=\left\{\left[\mathrm{Abs}_{\text {controle }}-\left(\mathrm{Abs}_{\text {amostra }}-\mathrm{Abs}_{\text {branco }}\right)\right] \times 100\right\} / \mathrm{Abs}_{\text {controle }}$

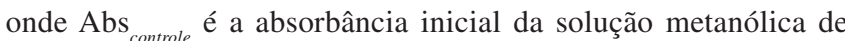

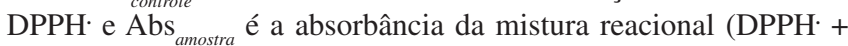
amostra).

\section{Cálculo de $\mathrm{CE}_{50}$}

As medidas da concentração eficiente $\left(\mathrm{CE}_{50}\right)$, que representa a concentração da amostra necessária para seqüestrar $50 \%$ dos radicais de DPPH, foram calculadas plotando a porcentagem de $\mathrm{DPPH}_{\text {remanescente }}(50 \%)$ versus as concentrações dos extratos de cada amostra.

A porcentagem de DPPH , ou seja, a quantidade de DPPH não reagida com os antioxidantes do café foi calculada através da Equação 2

$$
\mathrm{DPPH}_{\text {remanescente }}(\%)=\frac{\left[\mathrm{DPPH}^{\bullet}\right]_{T=t}}{\left[\mathrm{DPPH}^{\cdot}\right]_{T=0}} \times 100
$$

onde [DPPH $]_{\mathrm{T}=\mathrm{t}}$ é a concentração de DPPH no meio, após a reação com o extrato e [DPPH $]_{\mathrm{T}=0}$ é a concentração de DPPH , no início da reação (tempo zero). ${ }^{56}$

\section{Análises estatísticas}

Os resultados encontrados neste estudo correspondem à média de três repetições \pm desvio padrão da média. As médias foram analisadas estatisticamente pelo teste de Tukey, ao nível de $5 \%$ de probabilidade $(\mathrm{P}<0,05)$ aplicando-se ANOVA. Todas as análises foram realizadas usando o programa Microcal Origin 7.5.

\section{RESULTADOS E DISCUSSÃO}

Os teores de fenóis totais foram obtidos nas amostras de café conilon a partir da curva analítica de calibração do ácido gálico em concentrações conhecidas, e seu teor nas diferentes torras foi expresso como equivalentes de ácido gálico (EAG). Os resultados de fenóis totais, expressos em EAG por grama de café e em percentagem são apresentados na Tabela 1 .

Os resultados mostraram que a concentração de fenóis totais diminuiu de forma significativa com o aumento do grau de torra. Os teores de fenóis totais obtidos em todos os graus de torra para o café conillon foram relativamente superiores aos teores de fenóis totais descritos na literatura para o café arábica. ${ }^{46,57}$

Os teores de proantocianidinas (Tabela 1) foram determinados nas amostras de café conilon a partir da curva analítica de calibração da catequina em concentrações conhecidas.

A concentração de proantocianidinas nos extratos de café aumentou à medida que o grau de torra se acentuou, embora não tenha havido diferença significativa entre as torras clara e média. Entretanto, entre as torras clara e escura e entre as torras média e escura houve diferenças significativas. Como as proantocianidinas são taninos condensáveis, o aumento da temperatura sugere que o conteúdo deste constituinte foi gradualmente liberado da matriz do café e/ou formado com o rigor da torra, justificando assim a maior concentração destes polifenóis no café com torra escura. ${ }^{58} \mathrm{O}$ café conilon apresentou teores de proantocianidinas superiores aos obtidos para o café arábica. ${ }^{46}$

A determinação simultânea de cafeína, trigonelina, ácido cafeíco e ácido clorogênicos por CLAE-UV (Figura 1) foi feita com base na curva de calibração de cada substância, usando-se padrões analíticos para cada composto.

Analisando-se os resultados da Figura 1 observa-se que os teores de trigonelina diminuíram com grau de torra e que houve diferenças significativas da torra clara para a média e escura. Entretanto, os teores de trigonelina das torras média e escura não se diferenciaram significativamente. A trigonelina é rapidamente degradada durante o processo de torra, formando diversos produtos voláteis, como as piridinas, e outros como o $\mathrm{N}$-metil pirrol e a vitamina niacina, o que justifica a baixa concentração da trigonelina na torra escura. O café conillon apresentou teores de trigonelina inferiores aos citados na literatura para o café arábica, nas três torras. ${ }^{46}$

Os teores de ácidos clorogênicos diminuíram à medida que o grau de torra aumentou, e para o ácido 5-cafeoilquínico (5-ACQ) as diferenças entre as torras foram significativas. Os teores de 5-ACQ determinados no café conilon foram superiores ao do café arábica nas torras clara e média e inferiores à torra escura, tanto para amostras paranaenses como para amostras do cerrado mineiro. ${ }^{46,59}$

Tabela 1. Conteúdo de fenóis totais, proantocianidinas e atividade antioxidante do café conilon submetido a diferentes torras

\section{Café/Torras}

\begin{tabular}{|c|c|c|c|c|}
\hline & & Clara & Média & Escura \\
\hline \multirow[t]{2}{*}{ Fenóis Totais } & (mg eq. Ácido gálico $\mathrm{g}^{-1}$ café $\pm \mathrm{DP}$ ) & $89,21 \pm 0,92$ & $71,61 \pm 2,43$ & $63,71 \pm 1,69$ \\
\hline & Porcentagem (g 100g-1 café) & 8,92 & 7,16 & 6,37 \\
\hline \multirow[t]{2}{*}{ Proantocianidinas } & (mg eq. Catequina $\mathrm{g}^{-1}$ café $\pm \mathrm{DP}$ ) & $3,47 \pm 0,11$ & $3,91 \pm 0,10$ & $5,48 \pm 0,72$ \\
\hline & Porcentagem (g 100g-1 café) & 0,34 & 0,39 & 0,55 \\
\hline Atividade antioxidante (\%) & & $79,60 \pm 1,47$ & $67,90 \pm 2,26$ & $59,59 \pm 2,58$ \\
\hline \multirow[t]{2}{*}{$\mathrm{CE}_{50}$} & $\mu \mathrm{g} \mathrm{mL} L^{-1}$ & $63,69 \pm 1,51$ & $73,27 \pm 3,11$ & $84,11 \pm 4,12$ \\
\hline & $\mathrm{g} \mathrm{g}^{-1} \mathrm{DPPH}$ & $2,77 \pm 0,07$ & $3,18 \pm 0,13$ & $3,65 \pm 0,18$ \\
\hline
\end{tabular}




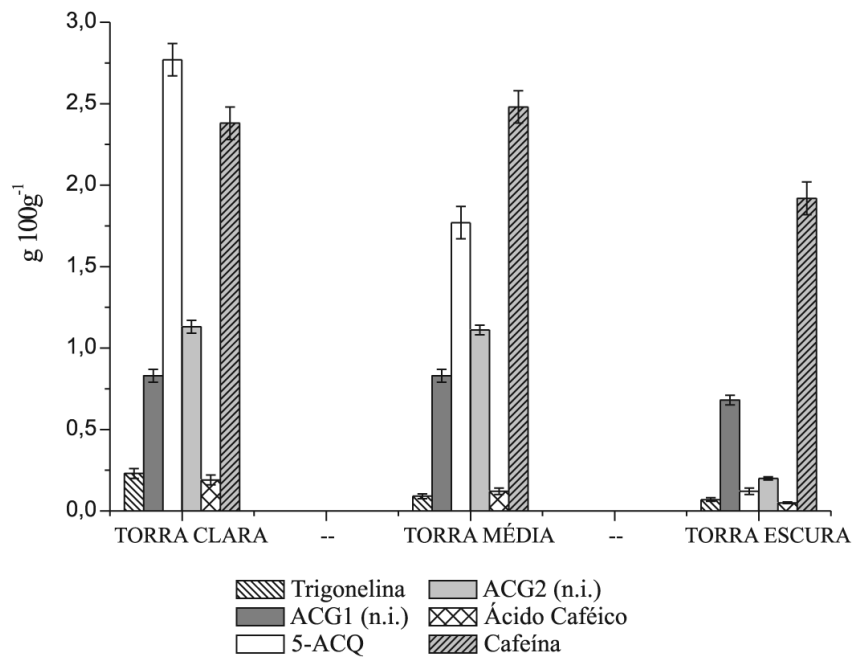

Figura 1. Distribuição percentual dos principais constituintes do café Conilon identificados por $C L A E-U V$

A variação nos teores de cafeína não foi significativa entre as torras clara e média, porém observa-se uma redução significativa na torra escura em relação às torras clara e média, provavelmente devido ao rigor da torra. $\mathrm{O}$ café conillon apresentou teores de cafeína superiores aos obtidos para café arábica em todas as torras. ${ }^{46,59}$

O ácido caféico, juntamente com os ácidos clorogênicos, também exerce ação antioxidante. ${ }^{60}$ Embora as diferenças tenham sido significativas, o teor de ácido caféico foi bastante baixo e diminuiu com o rigor da torra.

Nos últimos anos, compostos voláteis oriundos dos processos de torra também têm sido estudados como prováveis fontes de antioxidantes. ${ }^{24}$ Os teores de óleo essencial para o café conillon na torras clara, média e escura estão apresentados na Figura 2.

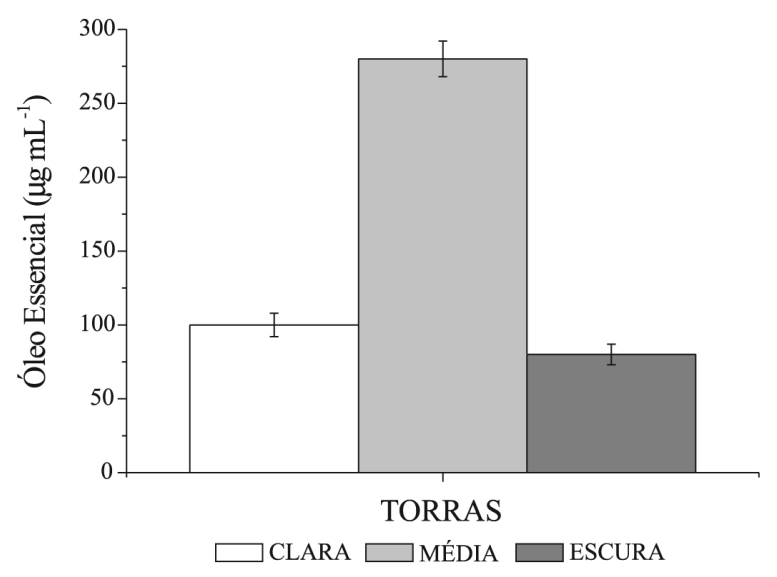

Figura 2. Rendimento do óleo essencial em diferentes graus de torra

O rendimento do óleo essencial da torra média foi superior ao das torras clara e escura e com diferenças significativas. Entre as torras clara e escura as diferenças não foram significativas. O rendimento superior de óleo essencial na torra média sugere que esta torra é mais aromática que as outras. Comparando-se o teor de óleo essencial do café conilon com o café arábica, o rendimento do conilon foi inferior nas torras clara e média, e superior na escura. ${ }^{46}$

O comportamento cinético da reação do DPPH em função da torra, na concentração de $100 \mu \mathrm{g} \mathrm{mL} \mathrm{m}^{-1}$, indica que todas as amostras atingiram o máximo de consumo do DPPH em 20 min. Não houve aumento significativo do consumo ao longo do tempo total de observação $(1 \mathrm{~h})$. A concentração eficiente $\left(\mathrm{CE}_{50}\right)$ foi calculada a partir do gráfico de $\mathrm{DPPH}_{\text {remanescente }}$ em função das concentrações, para os extratos de cafés obtidos nas diferentes torras com o tempo de 25 min de reação (Figura 3).

A Figura 3 mostra que houve correlação positiva entre a concen-

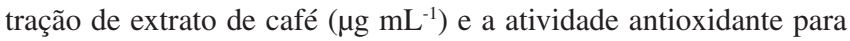
todas as torras, e que decresceu com o rigor da torra.

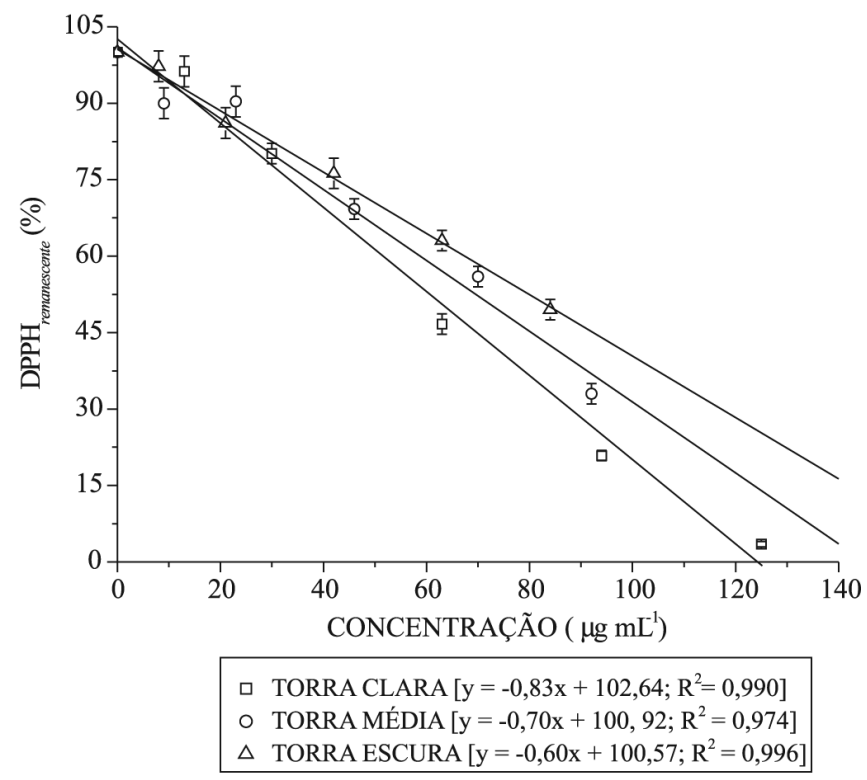

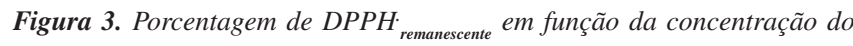
extrato de café nos diferentes tipos de torra

As porcentagens de atividade antioxidante (concentração de 100 $\mu \mathrm{g} \mathrm{mL} L^{-1}$ de extrato) e de $\mathrm{CE}_{50}$ (expressos em $\mu \mathrm{g} \mathrm{mL}^{-1}$ e em $\mathrm{g} \mathrm{g}^{-1} \mathrm{de}$ DPPH·) são apresentadas na Tabela 1.

Os resultados acima comprovam que a bebida de café conilon apresenta atividade seqüestradora do radical DPPH·nas três torras estudadas. As amostras submetidas à torra clara apresentaram maior percentagem de inibição de radicais DPPH. A quantidade necessária do extrato de amostras do café para reduzir a concentração inicial de DPPH· em $50 \%$ $\left(\mathrm{CE}_{50}\right)$ variou de $63,69 \pm 1,51$ na torra clara para $84,11 \pm 4,12 \mu \mathrm{g} \mathrm{mL} \mathrm{ma}^{-1}$ na torra escura, e as diferenças entre as três torras foram significativas.

As quantidades superiores dos compostos bioativos na torra clara (com exceção das proantocianidinas) resultaram na maior atividade antioxidante da bebida nesta torra. Embora na torra média tenha havido um aumento no rendimento de proantocianidinas e dos constituintes voláteis, estes constituintes aparentemente não tiveram a mesma importância dos fenóis totais e ácidos clorogênicos na atividade antioxidante. Valores de atividade antioxidante ligeiramente superiores para o café arábica em relação ao conilon (na concentração de $100 \mu \mathrm{g} \mathrm{mL}^{-1}$ ) foram observados na literatura. ${ }^{60}$

\section{CONCLUSÕES}

Os estudos realizados mostraram que a composição química da bebida do café conilon é dependente da torra.

$\mathrm{O}$ rendimento de óleo essencial na torra média foi superior às outras torras, tornando-a mais aromática. A torra escura resultou na diminuição de todos os compostos bioativos estudados, exceto as proantocianidinas.

Todos os extratos de café conilon estudados apresentaram atividades antioxidantes dependentes da torra e da concentração dos compostos bioativos. As amostras de café com grau de torra clara foram as que apresentaram maior porcentagem de atividade antioxidante frente ao DPPH. 


\section{AGRADECIMENTOS}

À CAPES, pela bolsa de mestrado de P. M. do Nascimento (S. A. L. Morais), ao Instituto de Química e ao Programa de Pós-Graduação em Química pelo suporte necessário.

\section{REFERÊNCIAS}

1. http://www.ansa.it/ansalatinabr/notizie/rubriche/entrevistas/200708011 12734390991.html, acessada em Outubro 2007.

2. Kobayashi, E. S.; Sakai, E.; Silva, E. A.; Pires, R. C. M. P.; $O$ Agronômico 2007, 59, 30.

3. Flament, I.; Coffee Flavor Chemistry, John Wiley \& Sons: West Sussex, 2002, cap. 5

4. Matiello, J. B.; O café: do cultivo ao consumo, Coleção do Agricultor, Editora Globo: São Paulo, 1991.

5. Malavolta, E.; História do café no Brasil, Ed. Agronômica Ceres Ltda: São Paulo, 2000, cap. 1 .

6. Aguiar, A. T. E.; Fazuoli, L. C.; Salva, T. J. G.; Favarin, J. L.; Bragantia 2005, 64, 577.

7. Martins, C. C.; Reis, E. F.; Busato, C.; Pezzopane, J. E. P.; Engenharia na Agricultura 2006, 14, 193

8. Kris-Etherton, P. M.; Hecker, K. D.; Bonanome, A: Coval, S. M. Binkosk, A. E.; Hilpert, K. F.; Griel, A. E.; Etherton, T. D.; Am. J. Med. 2002, 113, 71S.

9. Svilaas, A.; Sakhi, A. K.; Andersen, L. F.; Svilaas, T.; Ström, E. C.; Jacobs, D. R.; Jr., Ose, L.; Rune Blomhoff, R.; J. Nutr. 2004, 134, 562.

10. Sääksjärvi, K.; Knekt, P.; Rissanen, H.; Laaksonen, M. A.; Reunanen, A.; Männistö, S.; Eur. J. Clin. Nutr. 2007, 5, 1.

11. Ascherio, A.; Zhang, S. M.; Hernán, M. A.; Kawachi, I.; Colditz, G. A.; Speizer, F. E.; Willett, W. C.; Ann. Neurol. 2001, 50, 56.

12. Barranco, Q. J. L.; Allam, M. F.; Del Castillo, S. A.; Navajas, R. F. C.; Neurol. Res. 2007, 29, 91.

13. Bravi, F.; Bosetti, C.; Tavani, A.; Bagnardi, V.; Gallus, S.; Negri, E.; Franceschi, S.; La Vecchia, C.; Hepatology 2007, 46, 430.

14. Larsson, S. C.; Wolk, A.; Gastroenterology 2007, 132, 1740.

15. Adeney, K. L.; Williams, M. A.; Schiff, M. A.; Qiu, C.; Sorensen, T. K.; Acta Obstet. Gynecol. Scand. 2007, 86,161.

16. Bonita, J. S.; Mandarano, M.; Shuta, D.; Vinson, J.; Pharmacol. Res. 2007, 55, 187

17. Andersen, L. F.; Jacobs Jr., D. R.; Carlsen, M. H.; Blomhoff, R.; Am. J. Clin. Nutr. 2006, 83, 1039.

18. Merighi, S.; Benini, A.; Mirandola, P.; Gessi, S.; Varani, K.; Simioni, C. V.; Leung, E.; Maclennan, S. V.; Baraldi, P. G.; Borea, P. A.; Mol. Pharmacol. 2007, 72, 395.

19. Johnson-Kozlow, M.; Kritz-Silverstein, D.; Barrett-Connor, E.; Morton, D.; Am. J. Epidemiol. 2002, 156, 842.

20. Kawachi, I.; Willett, W. C.; Colditz, G. A.; Stampfer, M. J.; Speizer, F. E.; Archives of Internal Medicine 1996, 156, 521

21. Parras, P.; Martinez-Tome, M.; Jimenez, A. M.; Murcia, M. A.; Food Chem. 2007, 102, 582 .

22. Monteiro, M. C.; Trugo, L. C.; Quim. Nova 2005, $28,637$.

23. Stennert, A.; Maier, H. G.; Zeitschrift für Lebensmitteluntersuchung und-Forschung A 1994, 199, 198.

24. López-Galilea, I.; Paz De Peňa, I.; Cid, C.; J. Agric. Food Chem. 2007, 55,6110 .

25. Farah, A.; Paulis, T.; Trugo, L. C.; Martin, P. R.; J. Agric. Food Chem. $\mathbf{2 0 0 5}, 53,1505$.

26. Michael, P.; Purdon, M. P.; McCamey, D. A.; J. Food Sci. 1987, 52, 1680.

27. Yen, W. J.; Wang, B. S.; Chang, L. W.; Duh, P. D.; J. Agric. Food Chem. 2005, 53, 2658.

28. Nebesny, E.; Budryn, G.; Eur. Food Res. Technol. 2003, 217, 157.
29. Guyot, B.; Davrieux, F.; Manez, J. C.; Vincent, J. C.; Colloque Scientifique International sur le Café 1993, 2, 626.

30. Nogueira, M.; Trugo, L. C.; Ciênc. Tecnol. Aliment. 2003, 23, 296

31. Golluecke, A. P. B.; Taniwaki, M. H.; Tavares, D. Q.; Ciênc. Tecnol. Aliment. 2004, 24, 641.

32. Jacome, M. A. A.; Roucas, M. S.; De Maria, C. A. B.; Rosa, G.; Nutrire 2005, 30, 109 .

33. Moreira, D. P.; Monteiro, M; C.; Ribeiro-Alves, M.; Donangelo, C. M.; Trugo, L. C.; J. Agric. Food Chem. 2005, 53, 1399.

34. Castro, R. D.; Marraccini, P.; Braz. J. Plant Physiol. 2006, 18, 175.

35. Salgado, B. G.; Macedo, R. L. G.; Alvarenga, M. I. N.; Venturin, N.; Rev. Árvore 2006, 30, 343

36. Sette, L. D.; Passarini, M. R. Z.; Delarmelina, C.; Salati, F.; Duarte, M. C. T.; World J. Microbiol. Biotechnol. 2006, 22, 1185.

37. Partelli, F. L.; Vieira, H. D.; Monnerat, P. H.; Viana, A. P.; Rev. Bras. Ciênc. Solo 2006, 30, 443.

38. Fernandes, M. S.; Pereira, A. F. G. R.; Pinto, D. V. A. N.; Nery, C. M.; Pádua, M. R. F.; Ciênc. Agrotec. 2003, 27, 1076.

39. Farah, A.; Monteiro, M. C.; Calado, V.; Franca, A. S.; Trugo, L. C.; Food Chem. 2006, 98, 373

40. Morais, S. A. L.; Nascimento, E. A.; Chang, R.; Aquino, F. J. T.; Rev. Ceres 2002, 49, 295.

41. Nascimento, E. A.; Morais, S. A. L.; Rocha, R. S.; Ciênc. Tecnol. Aliment. 2003, 23, 282

42. Nascimento, E. A.; Aquino, F. J. T.; Morais, S. A. L.; Oliveira, G. S.; Cafeicultura 2006, 11, 24.

43. Morais, S. A. L.; Nascimento, E. A.; Aquino, F. J. T.; Alves, B. H. P.; Chang, R.; Ciência \& Engenharia 2007, 16, 9.

44. Morais, S. A. L.; Nascimento, E. A.; Aquino, F. J. T.; Nascimento, P. M.; Chang, R.; Ciência \& Engenharia 2007, 16, 23.

45. Morais, S. A. L.; Aquino, F. J. T; Chang, R.; Nascimento, E. A.; Oliveira, G. S.; Santos, N. C.; Coffee Science 2007, 2, 97.

46. Morais, S. A. L.; Aquino, F. J. T.; Nascimento, E. A.; Oliveira, G. S.; Chang, R.; Santos, N. C.; Rosa, G. M.; Ciênc. Tecnol. Aliment. 2008, 28 (Supl), 198.

47. http://www.abic.com.br/arquivos/pqc_guia_pratico_jan05.pdf, acessada em Agosto 2007.

48. http://www.sweetmarias.com/roasting-VisualGuideV2.html, acessada em Agosto 2007.

49. Instituto Adolfo Lutz; Normas analíticas, métodos físicos e químicos para análise de alimentos, 3ª ed., São Paulo, 1985, vol. 1.

50. Morais, S. A. L.; Nascimento, L. S. R.; Oliveira, G. S.; Evandro, A. N.; Chang, R.; Ciência Florestal 2007, 17, 145.

51. Godefroot, M.; Sandra, P.; Verzele, M.; J. Chromatogr. 1981, 203, 325.

52. Vitorino, M. D.; França, A. S.; Oliveira, L. S.; Borges, M. L. A.; Revista Brasileira de Armazenamento 2001, 26, 17.

53. Brand-Williams, W.; Cuvelier, M. E.; Berset, C.; Food Sci. Technol. 1995, 28, 25.

54. Sánchez-Moreno, C.; Larrauri, J. A.; Saura-Calixto; F.; J. Sci. Food Agric. 1998, 76, 270.

55. Yildirim, A.; Mavi, A.; Kara, A. A.; J. Agric. Food Chem. 2001, 49, 4083.

56. Sousa, C. M. de M.; Rocha e Silva, H.; Vieira-Jr., G. M.; Ayres, M. C. C.; da Costa, C. L. S.; Araújo, D. S.; Cavalcante, L. C. D.; Barros, E. D. S.; Araújo, P. B. de M.; Brandão, M. S.; Chaves, M. H.; Quim. Nova 2007, 30, 351 .

57. Heloisa, H. S.; Celeste, M. P. A.; Ciênc. Agrotec. 2006, 30, 112

58. Haslam, E.; Plant polyphenols: vegetable tannins revisited; University Press: Cambridge, 1989.

59. Alves, S. T.; Dias, R. C. E.; Benassi, M. T.; Scholz, M. B. S.; Quim. Nova 2006, 29, 1164

60. Santos, M. H.; Batista, B. L.; Quim. Nova 2007, 30, 604 